\title{
Detection of Wakashio oil spill off Mauritius using Sentinel-1 and 2 data: Capability of sensors, image transformation methods and mapping ${ }^{\text {is }}$
}

\author{
Sankaran Rajendran ${ }^{\mathrm{a}, ~ *}$, Ponnumony Vethamony ${ }^{\mathrm{a}}$, Fadhil N. Sadooni ${ }^{\mathrm{a}}$, \\ Hamad Al-Saad Al-Kuwari a, Jassim A. Al-Khayat a, Vashist O. Seegobin ${ }^{\text {b, }}$ \\ Himanshu Govil ${ }^{\mathrm{c}}$, Sobhi Nasir ${ }^{\mathrm{d}}$ \\ a Environmental Science Center, Qatar University, 2713, Doha, Qatar \\ ${ }^{\mathrm{b}}$ Department of Biosciences and Ocean Studies, University of Mauritius, Le Réduit, Mauritius \\ ${ }^{\mathrm{c}}$ Department of Applied Geology, National Institute of Technology, Raipur, India \\ d UNESCO Chair for Ophiolite Studies, Sultan Qaboos University, Al-Khod, 123, Muscat, Oman
}

\section{A R T I C L E I N F O}

\section{Article history:}

Received 22 September 2020

Received in revised form

22 January 2021

Accepted 25 January 2021

Available online 29 January 2021

\section{Keywords:}

Sentinel data

Image processing methods

Wakashio oil spill

Mauritius

Indian Ocean

Thickness of oil spill

\begin{abstract}
A B S T R A C T
Oil spill incidents contaminate water bodies, and damage the coastal and marine environment including coral reefs and mangroves, and therefore, monitoring the oil spills is highly important. This study discriminates the Wakashio oil spill, which occurred off Mauritius, located in the Indian Ocean on August 06, 2020 using the Sentinel- 1 and 2 data acquired before, during and after the spill to understand the spreading of the spill and assess its impact on the coastal environment. The interpretation of VV polarization images of Synthetic-Aperture Radar (SAR) C-band $(5.404 \mathrm{GHz})$ of Sentinel-1 acquired between July 5 and September 3, 2020 showed the occurrence and distribution of oil spill as dark warped patches. The images of band ratios $(5+6) / 7,(3+4) / 2,(11+12) / 8$ and $3 / 2,(3+4) / 2,(6+7) / 5$ of the Sentinel-2 data detected the oil spill. The images of decorrelated spectral bands 4,3 and 2 distinguished the very thick, thick and thin oil spills in a different tone and showed clearly their distribution over the lagoon and offshore, and the accumulation of spilled oil on the coral reefs and along the coast. The distribution of post-oil spill along the coast was interpreted using the images acquired after 21 August 2020. The accuracy of oil spill mapping was assessed by classifying the SAR-C data and decorrelated images of the MultiSpectral Instrument (MSI) data using the Parallelepiped supervised algorithm and confusion matrix. The results showed that the overall accuracy is on an average 91.72 and $98.77 \%$, and Kappa coefficient 0.84 and 0.96 , respectively. The satellite-derived results were validated with field studies. The MSI results showed the occurrence and spread of oil spill having different thicknesses, and supported the results of SAR. This study demonstrated the capability of Sentinel sensors and the potential of image processing methods to detect, monitor and assess oil spill impact on environment.
\end{abstract}

๑) 2021 Elsevier Ltd. All rights reserved.

\section{Introduction}

Studies have demonstrated the use of data from both active and passive satellite sensors to detect, map and monitor oil spills (Garcia-Pineda et al., 2017, 2020; Akinwumiju et al., 2020; Bhangale et al., 2017; Pisano et al., 2015; Arellano et al., 2015). Synthetic

\footnotetext{
\& This paper has been recommended for acceptance by Maria Cristina Fossi.

* Corresponding author.

E-mail address: srajendran@qu.edu.qa (S. Rajendran).
}

Aperture Radar (SAR) beams are capable of interacting with physical surface of seawater and detect waves, ships, oil spills, or any physical object different from water surface (Ozigis et al., 2020; Suneel et al., 2019; Lang et al., 2017; Alpers et al., 2017). The dualpolarized (VV and HH) SAR C-band of Sentinel-1 is considered to be the most efficient tool to study oil spills (El-Magd et al., 2020; Xue et al., 2020; Bayramov et al., 2018; Prastyani and Basith, 2018; Stopa and Mouche, 2017). Recently, Chaturvedi et al. (2020) examined the oil spills of Persian Gulf using Sentinel-1 (SAR-C) imageries and demonstrated the significance of $\mathrm{VV}$ polarization for recognizing the oil-spills. SAR is capable of detecting marine oil 
spills, independent of time of the day or weather conditions, although the images have difficulty in separating oil spills from look-alikes. In such cases, optical sensor data is used to detect and map the areas of oil spills and validate the results of SAR (Arslan, 2018; Bayramov et al., 2018).

The high-resolution multispectral data of Sentinel-2A and 2B are available since June 2015 and March 2017, respectively, and these data can be used to map oil spill very effectively (GarciaPineda et al., 2020; ESA, 2020; Lu et al., 2019; Sun et al., 2018a, b; Kolokoussis and Karathanassi, 2018; Nadia et al., 2018). Literature review shows that oil film has a reflectance in the range 400-700 nm wavelength in contrast with background seawater (Liu et al., 2016; Otremba et al., 2013; Klemas, 2010; Ma et al., 2009; Lu et al., 2013a; Sun et al., 2011; Clark et al., 2010; Otremba and Piskozub, 2001). Several studies demonstrated the assessment accuracy of mapping the oil spills (Mdakane and Kleynhans, 2020; Ozigis et al., 2019; Sun et al., 2018b; Zhang et al., 2017). However, it is important to demonstrate suitable methods to map and monitor oil spills from satellite data, and assess the accuracy of mapping to evaluate the impacts of oil spills in the coastal and marine environments. Therefore, the present study aims at developing image processing methods to map the oil spill of Wakashio, which occurred off Mauritius in the Indian Ocean (Fig. 1) on August 06,

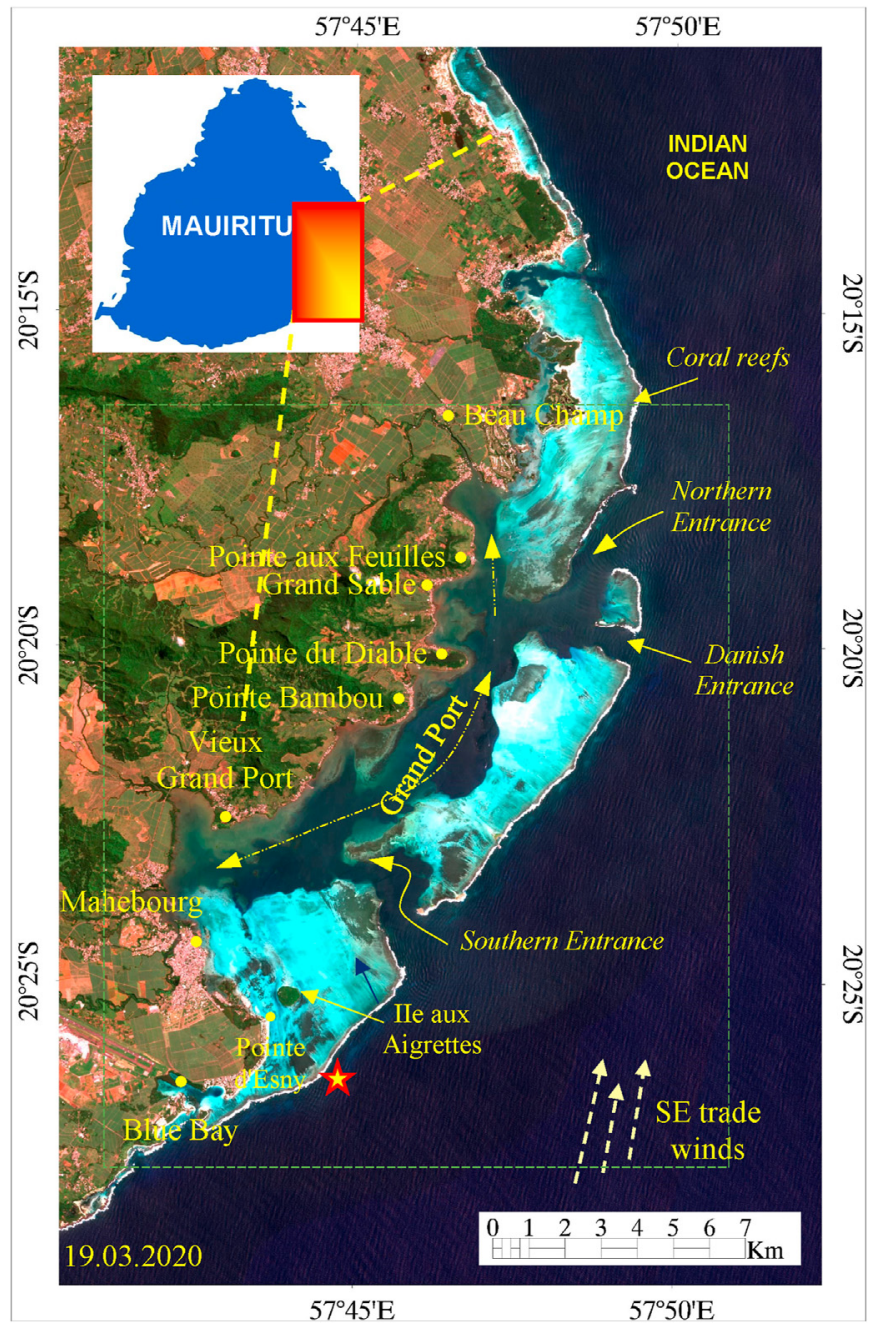

Fig. 1. True color image (R:4; G:3; $\mathrm{B}: 2$ ) of Sentinel-2 showing the distribution of coral reefs, directions of water circulation and wind in and around the study region (Dashed rectangle: Study area; Star: Incident site). (For interpretation of the references to color in this figure legend, the reader is referred to the Web version of this article.)
2020 and assess the accuracy of mapping as well as understand the impacts of the spill in and around the incident sites. The major objectives of the study are: 1) to characterize the spectral band's absorption of Sentinel- 1 and 2 sensors and develop image transformation methods to map the oil spill, 2) to detect and monitor the oil spill using the data acquired before, during and after the oil spill event, 3) to assess the accuracy of mapping and capability of sensors using the field studies and 4) to understand the spread of spill and its impacts on the coastal and marine environments.

\section{Oil spill of Wakashio and study area}

Oil spill from the Japanese bulk carrier 'Wakashio' (300 m long vessel built-in 2007; AFP, 2020a) occurred on August 06, 2020 near Pointe d'Esny about $3.2 \mathrm{~km}$ (star in Fig. 1) off the southeast coast off Mauritius (latitude: $20^{\circ} 10^{\prime} \mathrm{S}$ and longitude: $57^{\circ} 30^{\prime} \mathrm{E}$ ), when she ran aground on a coral reef while carrying 3900 metric tons of lowsulfur fuel oil, 200 metric tons of diesel from china to Brazil (Lewis, 2020). The British Admiralty Chart (WGS84-711 at $1: 125,000$ scale) shows that water depth around the incident site is $20 \mathrm{~m}$. The spill has occurred after 12 days when a crack developed on its hull, and the spill continued in the following weeks. The ship broke apart on August 16,2020, and scuttling of the forwarding section of the ship started on August 20, 2020. According to Mobilisation Nationale Wakashio, the sinking of the forward hull section was completed (the hull was submerged and no longer visible from the surface) on August 24, 2020 (Hand, 2020). The spill had occurred in an environmentally sensitive area protected under an international treaty for the conservation and sustainable use of wetlands known as the 'Ramsar Convention on Wetlands', which has rare biodiversity (Lewis, 2020). There was a big challenge to assess the oil spill and pollution in and around the site due to the remoteness of the location. Therefore, in this study, the area between Blue Bay and Beau Champ including the oil spill site is chosen for the study. It covers Grand Port (lagoon engulfed by coral reef ridges) and the coastal areas of Pointe d'Esny, Mahebourg, Vieux Grand Port, Pointe Bambou, Pointe du Diable, Grand Sable, and Pointe aux Feuilles including the Ile aux Aigrettes, a small island close to the Pointe d'Esny in the lagoon. The coastal area consists of a variety of habitats including beaches, sand or mud swamps, sand beds, reef zone lagoon channels, mangroves, seagrass beds, coral heads and colonies (Daby, 2003, 2006). There are dense fields of mixed coral colonies in the lagoons. Daby (2006) stated that the lagoons are generally shallow (average depth: $2 \mathrm{~m}$ ) and seagrasses often grow close to beaches and help to stabilize the sediments and provide nursery grounds for reef species.

\section{Satellite data and image processing methods}

In this study, detection of the oil spill of Wakashio was carried out using the available SAR-C data (frequency: $5.405 \mathrm{GHz}$ ) of Sentinel-1B acquired between July 05 and September 15, 2020 and MSI data of Sentinel-2 acquired between July 17 and September 10, 2020. Initially, the data were preprocessed and subsets of data that cover the area of oil spill in and around the incident site were performed. Subsequently, detection of the oil spill was studied using SAR-C data, and mapping of the oil spill was carried out using MSI data by image transformation methods, viz., band ratios and decorrelation stretch. An assessment of accuracy of mapping was performed by the classification of images using Maximum likelihood method and confusion matrix. Finally, the results were validated through field studies. All the Sentinel-1 and 2 data for the period between July 05 and September 15, 2020 were downloaded freely from the Copernicus Open Access Hub of European Space Agency. The sensor characters of Sentinel-1 and 2 and details of 
data used in this study are given in Tables 1 and 2 of Appendix-A. The image analyses were carried out using the Environment for Visualizing Images software (ENVI 5.5, Harris Geospatial Solutions, Broomfield, CO, USA; https://www.harrisgeospatial.com). The schematic diagram showing the method and workflow of the present study is presented in Fig. 2.

Detection of the oil spill of Wakashio has been carried out using the Sentinel-1B data acquired at ground range detected highresolution (GRDH) processing level in the interferometric wide swath (IW) mode, having a spatial resolution of $5 \mathrm{~m} \times 20 \mathrm{~m}$ in VV/ $\mathrm{VH}$ polarization. Pre-processing of the data was performed using the Sentinel Application Platform (SNAP; https://step.esa.int/main/ toolboxes/snap/) of European Space Agency (ESA), and the steps included removal of thermal and border noises, calibration, speckle filtering, terrain correction and conversion of images to $\mathrm{dB}$ (Fig. 2). SNAP extracts dark spots of the oil spill based on the contrast in the image using a pre-determined threshold. The resulted images were interpreted by analyzing the brightness of pixels by visual method, and pixel intensity values by developing horizontal profiles of oil spill areas and seawater (Chaturvedi et al., 2020; El-Magd et al., 2020). To understand the spreading of the oil spill and support the results of SAR data, we used the MSI spectral bands of Sentinel2 that have high spatial $(10,20$ and $60 \mathrm{~m})$ and 12-bit radiometric resolutions. Clouds affect the temporal resolution of optical images, and therefore, we have chosen data that have minimum cloud cover over the study area. The data used in this study were not processed for removing the clouds, as many pixel characteristics to the oil spill will be lost from the data in this process. Kolokoussis and Karathanassi (2018) stated that oil and oil/water mixtures have absorption features that are distinct from water and clouds. The data were preprocessed using the Quantum GIS (QGIS 3.6, https://qgis.org/) a free and open-source Geographic Information System.

Mapping of oil spill was carried out using the band ratios $(5+6) /$ $7,(3+4) / 2,(11+12) / 8$ and 3/2, $(3+4) / 2,(6+7) / 5$ (Rajendran et al., 2020a, b; 2013, 2011). We interpreted the image spectra of MSI to understand the spectral band absorptions, developed band ratio images and decorrelated images to map the oil spill (Sun et al., 2018a; Kolokoussis and Karathanassi, 2018). The occurrence and distribution of different thickness of oil spills of the study area were studied by decorrelation of the spectral bands 4,3 and 2 by decorrelation stretch method (Gillespie et al., 1986; Rothery, 1987; Rajendran et al., 2012, 2020a; Rajendran, 2016; Abrams et al., 1988). In this study, the visual interpretation of images has been considered as one of the most effective methods to study the spread of oil spills and associated features (Bradford and Sanchez-Reyes, 2011; Vergara et al., 2016). The accuracy of the mapping of Wakashio oil spill was assessed by classifying the SAR-C data and the decorrelated images of MSI data using Parallelepiped supervised algorithm and confusion matrix (Congalton, 1991; Richards and Jia, 1999; Ganasria and Dwarakisha, 2015; Rajendran et al., 2016, 2018; Lee et al., 2018). The Parallelepiped algorithm is one of the most simple and accurate classification techniques works on the division of every axis of a multidimensional feature vector (CastillejoGonzalez et al., 2009; Ganasria and Dwarakisha, 2015; Lee et al., 2018). The confusion matrix assesses the accuracy of classification when the mapping of oil spills is costlier and time-consuming in the incident site (Sun et al., 2018b; Zhang et al., 2017). In this study, the overall accuracy (OA) and kappa coefficients $(\mathrm{KC})$ are calculated quantitatively to evaluate the classification of the Wakashio oil spills. The overall accuracy is calculated by summing the number of correctly classified values and dividing it by the total number of values. The kappa coefficient is a measurement from the agreement between classification and truth values. The kappa values of 1 and 0 signify perfect agreement and no agreement, respectively. During this process, the SAR-C data $(1964 \times 2031$ pixels $)$ were classified into three classes, viz., oil spill, seawater and land, based on the training ROIs (region of interests, the truth values) using the backscatter values obtained from the horizontal profiles (17 to -26 representing oil spill, -14 to -18 for water surface and -8 to -15 for land feature; section 5.1.1). The decorrelated images of MSI $(469 \times 454$ pixels) were classified for very thick, thick and thin types of oil spills based on the training ROIs and an analyst's prior knowledge of the study area. To select ROIs, the image interpretation of oil spills over the decorrelated images were considered (section 4.2). The accuracy of the classified images was assessed by estimating the overall accuracy and Kappa value (Congalton, 1991). Moreover, several field studies were carried out during the incident to assess the occurrence and spread of the oil spill and validation of the results of image analysis. Aerial images and field photographs were taken during the fieldwork using a drone (DJI Mavic Air 2) and a field camera.

\section{Results and discussion}

\subsection{Oil spill mapping of SAR}

In this study, to understand the oil spill of Wakashio and the accumulation of spilled oil in the study area, we interpreted the VV

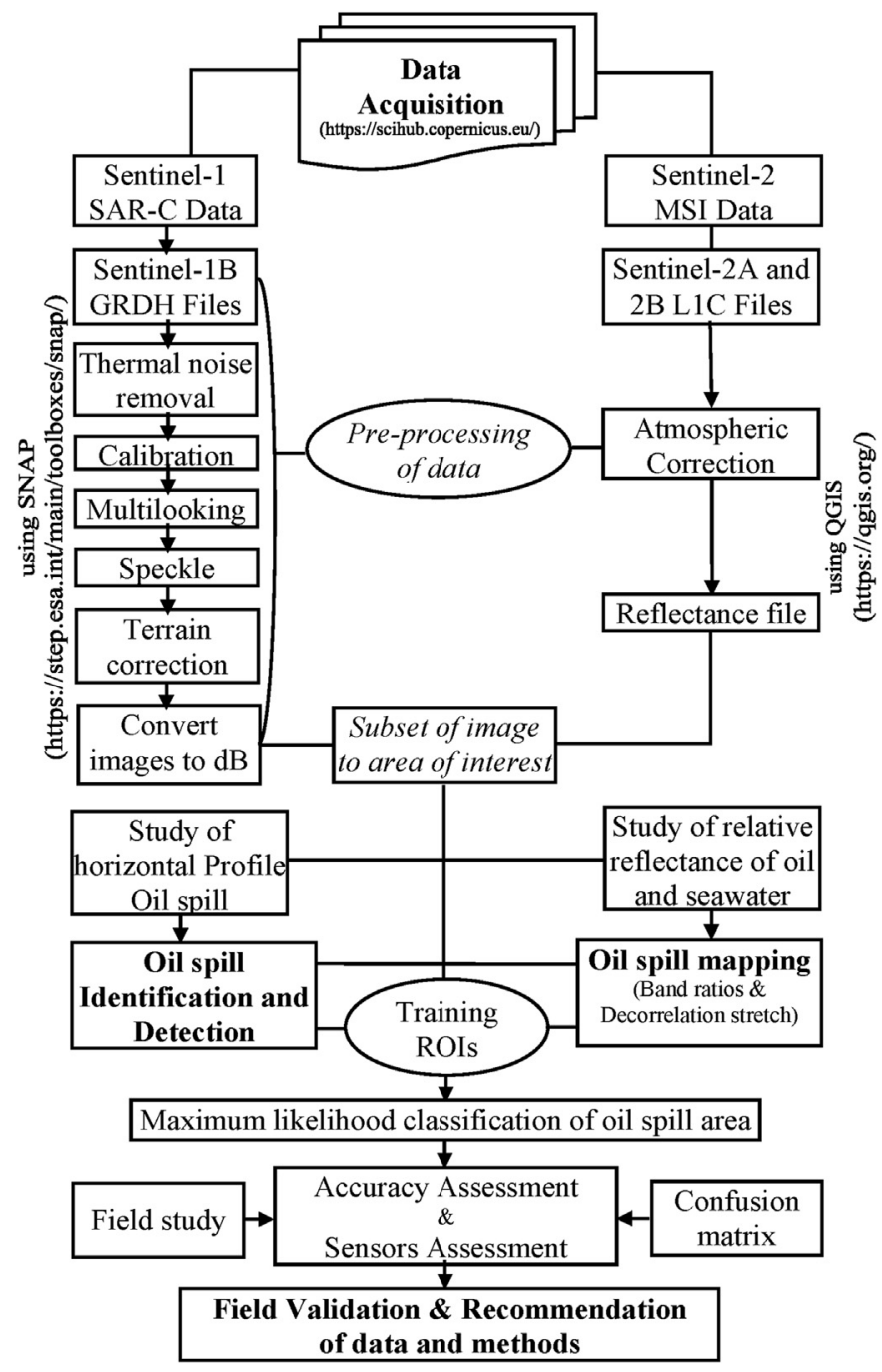

Fig. 2. Schematic diagram showing the pre-processing and image analysis of Sentinel1 and 2 data and assessment of accuracy for mapping of the oil spill of Wakashio. 
images of SAR (Fig. 3). The image acquired on July 17, 2020 before the incident is given in Fig. 3a. It shows the Indian Ocean monsoon waves, lagoon with calm water, distribution of coral reefs and coral reef ridges that protect the lagoon and coast from offshore waves as fine to medium texture and grey to dark tone. The absence of ship and oil spill, i.e., before the spill, can be interpreted in the incident site (star marked, also checked with the image of July 05, 2020, Fig. 1a in Appendix-B). The water in the southern and northern entrances appear clearly. The land and its features (including manmade features) exhibit light to dark tone with fine to medium textures. The coastline of the study area is sharp and distinct between land and lagoon water. The images of August 10 and 16 (Fig. 3b and c) show the presence of Wakashio and visiting ships as bright objects in the longitudinal orientation of the incident site. The Wakashio was oriented in the NE direction on August 10 and the broken parts were in different directions on August 16, 2020. The image acquired on September 15, 2020 shows the absence of Wakashio (Fig. 3d). Also, the interpretation of images acquired on August 21 and 22 show the presence of poop section as a spot in the incident site and absence of the section on September 03, 2020 (Fig. 1b, c \& d in Appendix-B). The interpretation of images confirms that the ship was broken on August 16 (AFP, 2020b) and the forward hull section of the ship was absent due to scuttling which started on August 20, 2020 (Hand, 2020). The study of all images shows that the direction of approach of winds and waves were towards NE in July and August 2020 (Fig. 3), that is towards the coast, which can be assessed from the direction of movement of oil spill in the lagoon.
The interpretation of oil spills over the images acquired during August 2020 shows the presence of oil spill clearly, as dark warped patches with the spreading width (Fig. $3 \mathrm{~b}$ and $\mathrm{c}$ ). The spilled oil moved towards the coast over the coral reefs by crossing the coral reef ridge and Ile aux Aigrettes (Fig. 3b). Though the images are not able to show the thickness of the spilled oil and oil types (GarciaPineda et al., 2020), the variations in the thickness can be interpreted and assessed from the shades of the darkness, especially when the oil spill was adequate in the site (could be seen from the backscatter values of oil in the horizontal profile). The detection of oil spills and surface waves is due to the VV polarization of SAR that provides more radar backscatter and high dielectric constant of the sea surface (Wei $\beta$ et al., 2020). The image acquired on August 10, 2020 shows the accumulation of spilled oil along the coast near the Blue Bay, Pointe d'Esny, Mahebourg, Vieux Grand Port, Pointe Bambou, Pointe du Diable, Grand Sable, Pointe aux Feuilles and Beau Champ. The image exhibits the concentration and spread of oil along the coast and in the lagoon (Fig. 3b). The oil spill patches observed at the northern entrance may be due to the movement of oil parallel to the reef ridge when a huge volume of oil spill happened on August 06, 2020 (see section 5.2.2). The images acquired on August 16, 2020 show less oil spills from the incident site (Fig. 3c). The study of images of the August 21 and 22, and September 03 and 15, 2020 episodes presents the occurrence of post-oil spill that found after the forecastle section was taken away from the incident site (Figs. $3 \mathrm{~d}$ and $1 \mathrm{~b}, \mathrm{c} \& \mathrm{~d}$ in Appendix-B). The occurrence of post-oil spills over the lagoon may be due to the circulation of water and accumulation or concentration of oil or oil
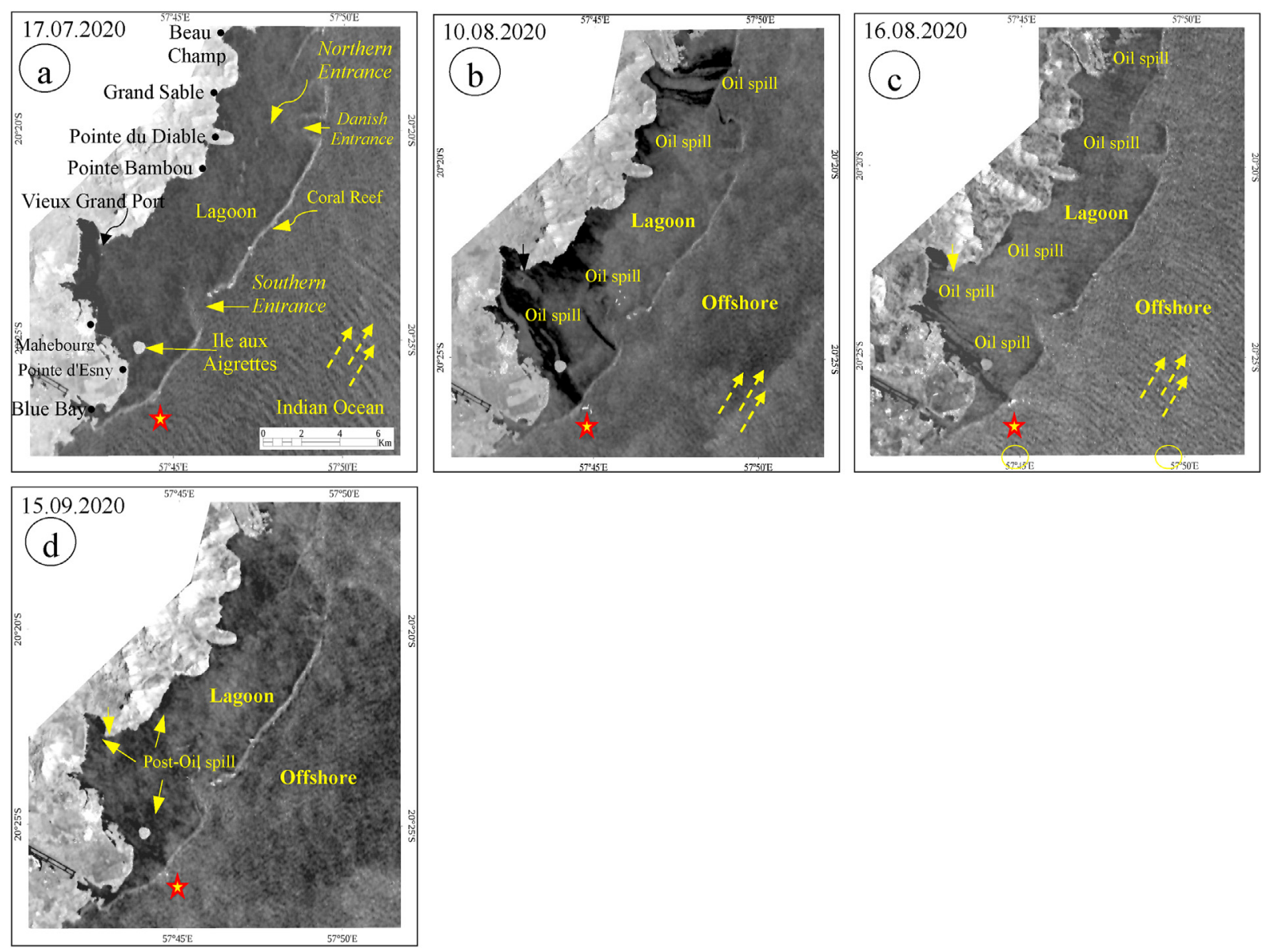

Fig. 3. VV images of SAR showing the occurrence of oil spill as dark patches in the lagoon during and after the incident (Star locates the incident site). 
sludge over the coral reefs. The image of September 15, 2020, shows poor accumulation of spilled oil in the lagoon, compared with the images of previous dates. The analysis of horizontal profiles over the offshore, lagoon, and oil spill using the VV image acquired on August 10, 2020 shows significant variations in the backscatter values (Fig. 4). However, it is unfortunate that no images show the presence of oil spills in and around the ship and in the offshore clearly, while the aerial images show the release of huge volumes of oil and different thickness of oil spill in and around the ship (section 6).

\subsubsection{Horizontal profiles of oil spill}

Fig. 4 shows the locations (Fig. 4a) and horizontal profiles (Fig. 4b) measured (left to right) for 241 pixels over the offshore, lagoon, oil spill and land areas. The backscatter values between the incidence near $30.29^{\circ}$ and incidence far $45.69^{\circ}$ angles for the features show significant variations. The interpretation of profiles of offshore (HP1_SEA to HP3_SEA) and lagoon (HP1_GP to HP3_GP) does not show much variation in the backscatter values. The values range between -12 and -18 , whereas, the profiles measured across the oil spill areas, viz., 1) across a linear oil spill (red, HP1_GP_OIL), 2) across the three linear oil spills (orange, HP2_GP_OIL) and 3) across an oil spill accumulation (from land to sea) (magenta, HP3_GP_OIL) show a significant variation in the backscatter values. The profile of linear oil spill (Fig. 4b; red, HP1_GP_OIL) shows low backscatter values ( -18 to -24 ), where the pixels 169-201 represent the oil spill. Similarly, the profile measured over the three linear oil spills (orange, HP2_GP_OIL) shows low backscatter values from -17 to -26 at three locations. Values from -14 to -18 are for water surface. The water surface that occurred in-between the oil spills show backscatter values from -17 to -18 . As well, the profile measured from land to lagoon through an oil accumulation (magenta, HP3_GP_OIL) shows high backscatter values from -8 to -15 representing the land feature, and low values from -16 to -18 represent the water surface of lagoon. The profiles showing very low values from -17 to -24 represent the occurrence of oil accumulation. Overall, the profiles show backscatter values from -14 to -18 representing the water surface and from -17 to -26 representing the oil spill and its accumulation; the horizontal profiles well distinguished the land, water and oil spill (Fig. 4b; El-Magd et al., 2020). However, the detection of oil spills by the SAR depends on the type of oil, thickness, concentration, spread of oil, and interpretation of images having look-alike features, which are commonly found in the SAR images.

\subsection{Oil spill mapping of MSI}

We analyzed image spectra of MSI to understand the spectral bands that characterize the oil spill (Rajendran et al., 2020a, b). The analysis shows that the spectral bands 3 and 4 of MSI are good to detect the oil spill (Rajendran et al., 2020a, b; Fingas and Brown, 2018; Sun et al., 2018a; Kolokoussis and Karathanassi, 2018; Lu et al., 2013b, 2009, 2008; Clark et al., 2010). Based on the spectral band's absorption, band ratios and decorrelated stretch images were developed using the data acquired between July 17, 2020 and September 10, 2020 that cover before, during and after the oil spill incident. The results are given in Figs. 5-7, and Appendix-B.

The images of the ratio $(5+6) / 7,(3+4) / 2,(11+12) / 8$ show the land, Ile aux Aigrettes and reef ridge in cyan blue and coarse texture, the offshore water in red to light magenta with medium to fine textures, and the lagoon in light brown to orange with fine texture (Fig. 5). The clouds over the images appear light blue to light green and medium texture. The image acquired on July 17, 2020, before the oil spill, shows the absence of ship (Fig. 5a), whereas the images acquired during August 01, 06, 11, and 16, 2020 show the presence of ship and the oil spill around the incident site. The image acquired on September 05, 2020 did not show the ship since it was under scuttling from August 20, 2020 (Fig. 5f). The images of August 01 and 16, 2020 show the presence of suspended sediments around the ship due to the grounding and breaking of the ship. The oil spills in and around the ship appear in light blue (very thick oil spill) to bright white (thick oil spill) to light orange (thin oil spill) with fine texture, and the spills are distinguishable from light tone (Fig. 5b and c). The distribution of spilled oil over the lagoon show shades of orange, and the spread can be well interpreted on the image acquired on August 06, and 16, 2020 compared to the image of August 11, 2020 (Fig. 5c, d \& e, and Fig. 2a-e in Appendix-B). The occurrence of post-oil spill over the lagoon and offshore is very evident on the image acquired on September 05, 2020 (Fig. 5f). The MSI images do not exhibit the direction of approach of winds and waves in offshore as observed in the SAR images (Figs. 3 and 5).

The images of band ratio $3 / 2,(3+4) / 2,(6+7) / 5$ show the land, Ile aux Aigrettes and reef ridge in purple and coarse texture, the offshore in dark brownish blue and fine texture, and the lagoon in shades of orange with fine to medium textures (Fig. 6). The oil spills in and around the ship exhibit dark grey (very thick oil spill) to bright yellow (thick oil spill) to light orange (thin oil spill) with fine texture (Fig. 6c). The distribution of oil in offshore and over the lagoon exhibits shades of orange and can be well interpreted on the
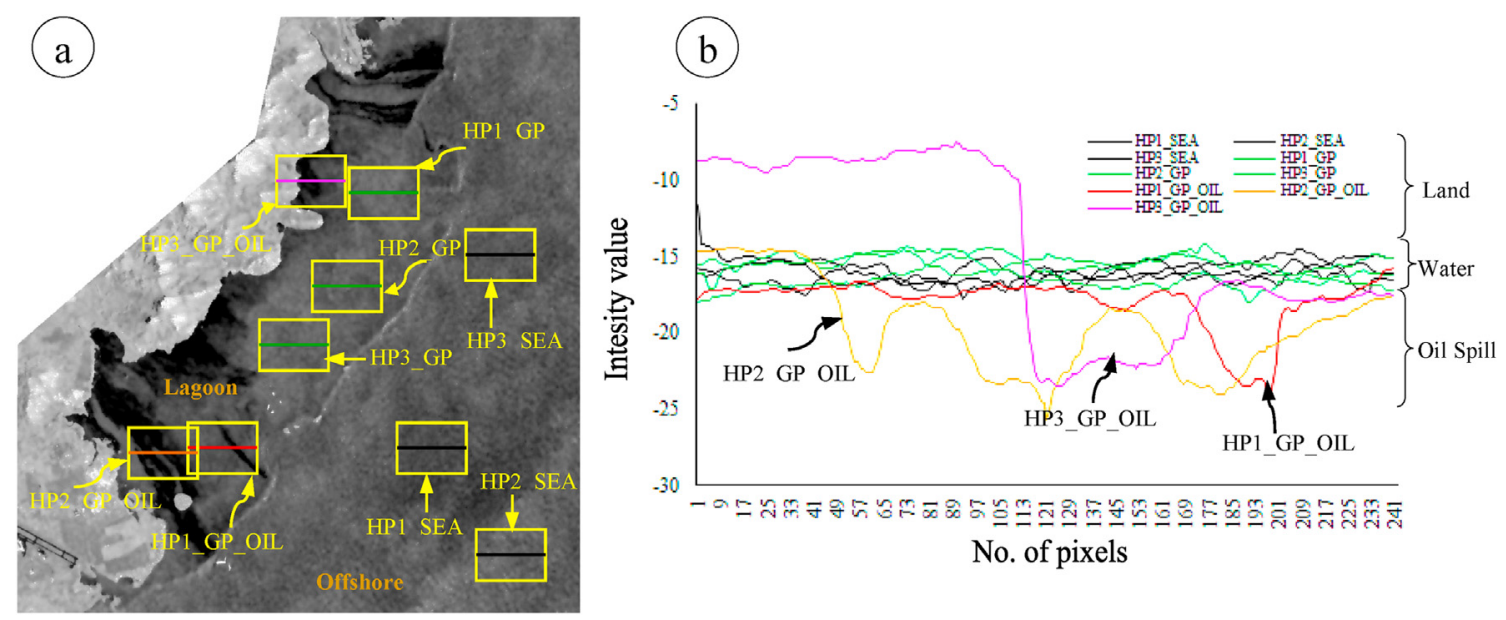

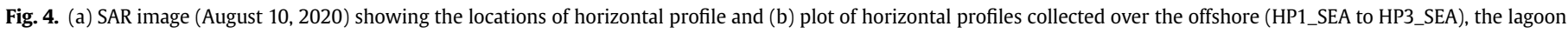
(HP1_GP to HP3_GP) and the oil spill (HP1_GP_OIL to HP3_GP_OIL). 

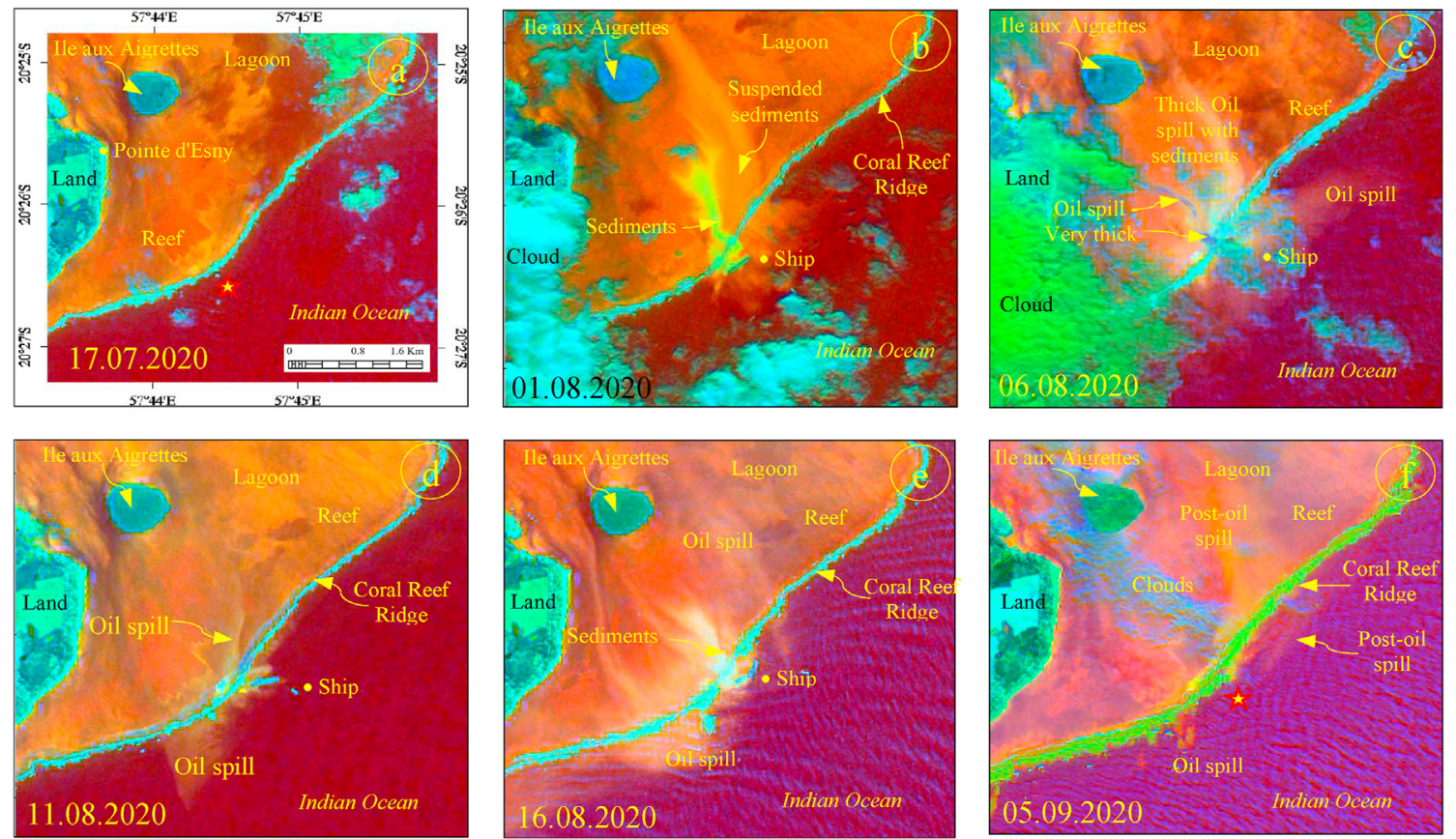

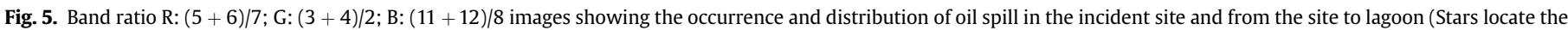
incident site).
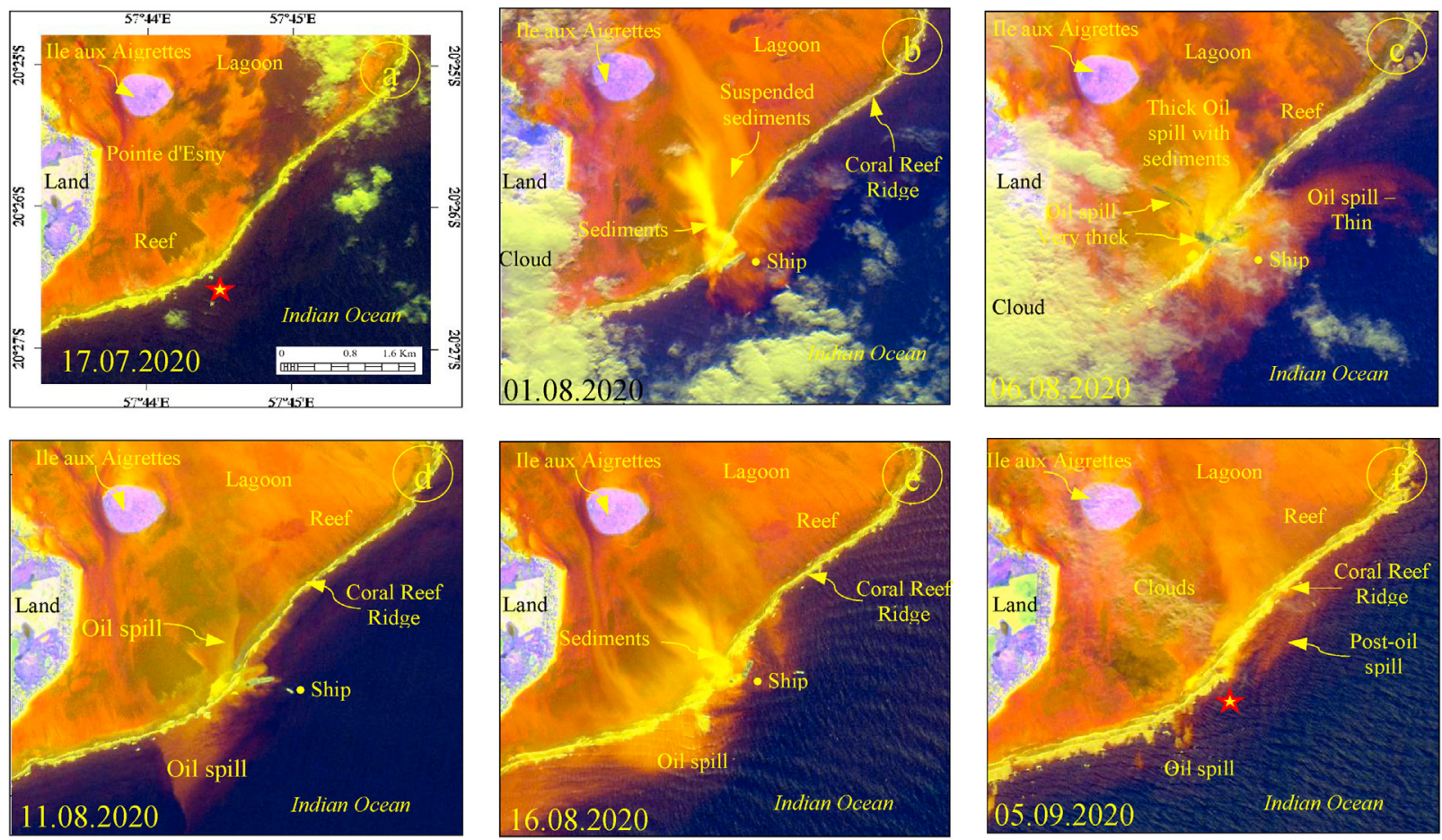

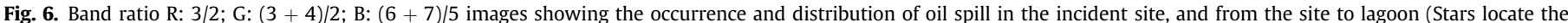
incident site).

image acquired on August 06, and 16, 2020 and assessed from the transparency of the coral reefs (Fig. $6 \mathrm{c}$ and e, and Fig. 3a-e in Appendix-B). The suspended sediments due to the grounding and breaking of the Wakashio exhibit brighter tone on the images acquired on August 01 and 16, 2020 and the concentration of sediments can be assessed from the intensity of brightness. The image of September 05, 2020, shows the presence of post-oil spill in the lagoon and offshore. The oil spill in the offshore dispersed and moved towards the northeast parallel to the coral reef ridge (Fig. 6f). The interpretation of regional images of band ratios showed clearly the dispersion of oil spills on both the sides of Ile aux Aigrettes and spread over the lagoon (Fig. 3a-e in Appendix-B). 

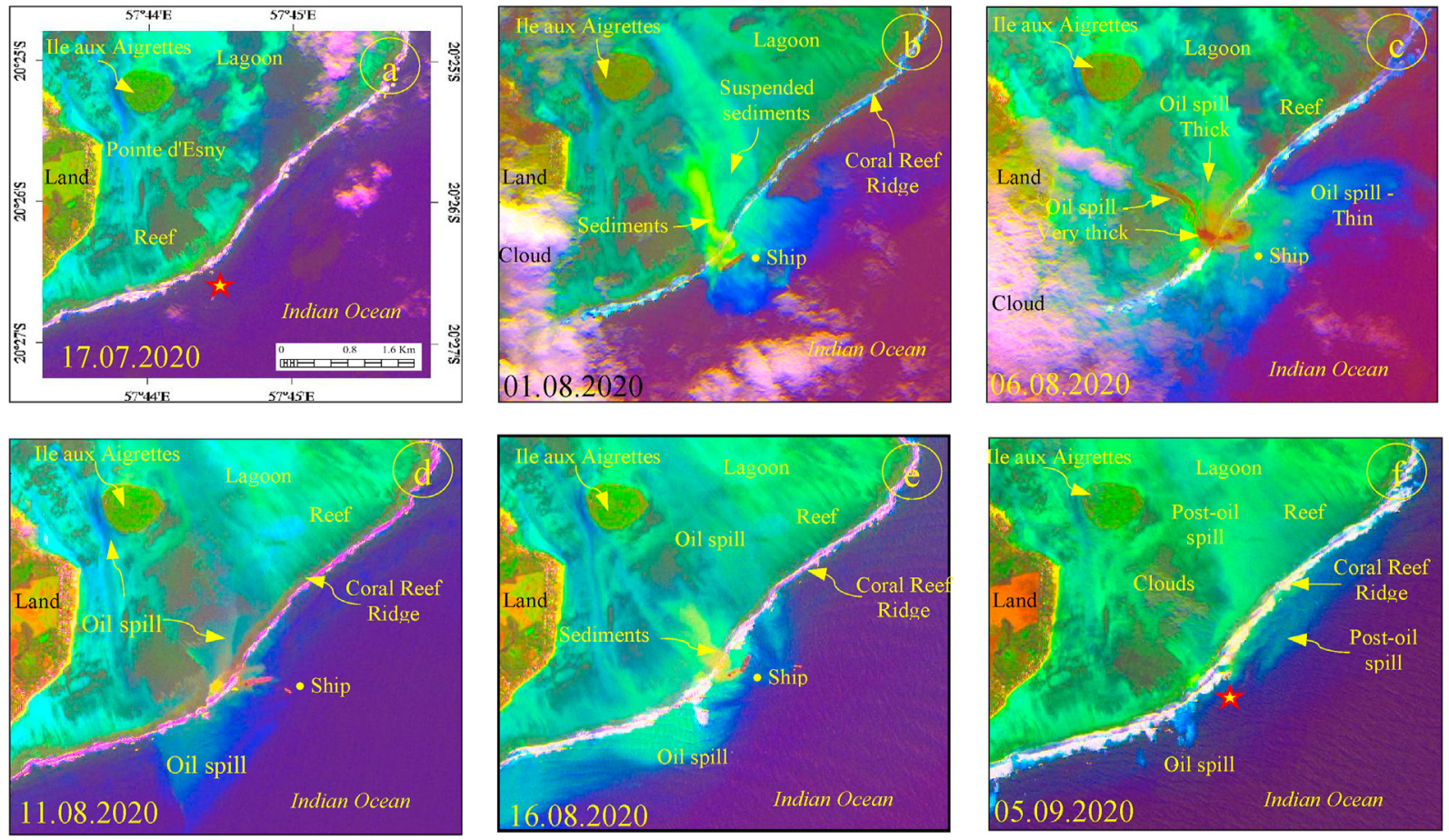

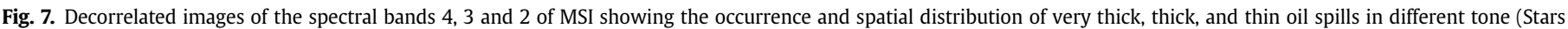
locate the incident site).

The accumulation of oil can be interpreted along the coast near the Blue Bay, Pointe d'Esny, Mahebourg, Vieux Grand Port, Pointe Bambou, Pointe du Diable, Grand Sable, Pointe aux Feuilles, and Beau Champ, in the lagoon and over the coral reefs in light grey and fine texture. No significant occurrence of oil spill observed on the image acquired on September 10, 2020 after the oil spill event (Fig. 3e in Appendix-B). Both the band ratios $(5+6) / 7,(3+4) / 2$, $(11+12) / 8$ and $3 / 2,(3+4) / 2,(6+7) / 5$ detected well the oil spills, but still the thickness of the oil spills and spread is not well distinguished from other features by the band ratios images. Thus, we decorrelated the spectral bands 4,3 , and 2 to understand the thickness and spread of the oil spills (Rajendran et al., 2020a). The resulted images are given in Fig. 7.

The images show the thin oil spill in light bluish-green, fine texture, and wide flow pattern distinctly (Fig. 7c). The thick oil spill appears in greenish-yellow, fine texture, and narrow flow pattern with the thin oil spill in the images. The very thick oil spill exhibits brown tone, fine texture, and linear flow pattern in the image acquired on August 06, 2020 (Fig. 7c). All the images show clearly the distribution of spilled oil offshore in light blue, bluish-green and brown, and can be compared with the band ratios images (Figs. 5 and 6). The detection allows assessing the thickness of spilled oil, which also depends on the presence of suspended sediments. The images show the spread of oil from the incident site towards lagoon by crossing the coral reef ridge and confirm the spread of oil offshore. The suspended sediments of the region appear in bright yellow to yellow. The interpretation of regional images (Fig. $4 a-e$ in Appendix-B) well confirms the dispersion of oil spills on both sides of Ile aux Aigrettes and spread over the lagoon. The accumulation of oil along the coast near Blue Bay, Pointe d'Esny, Mahebourg, Vieux Grand Port, Pointe Bambou, Pointe du Diable, Grand Sable, Pointe aux Feuilles, and Beau Champ, over the lagoon and coral reefs can be well interpreted in the shades of light blue tone and fine texture. For example, the existence of shades of light bluish tone along the coral reef boundaries over the images of August 11 and 16, and
September 05 compared with the image of August 01, 2020. The image of September 05, 2020 (Figs. 7f and 4d in Appendix-B), shows the oil spill that moved towards the northeast parallel to the coral reef ridge from the incident site. The image acquired on September 10, 2020 shows no significant occurrence of oil spill except near the Blue Bay and Pointe Bambou (Fig. 4e in AppendixB). The decorrelated images (Fig. 7) detected well the thickness and showed well the spread of the oil spill. The detections support the interpretations of band ratios images (Figs. 5 and 6). A comparative study of the results of MSI images (Figs. 5-7) with the results of SAR images (Fig. 3) shows that the SAR images did not exhibit the very thick, thick and thin oil spills as observed in the MSI images. In addition, the SAR images did not show the occurrence of oil spills around the ship and offshore as interpreted over the MSI images. Though most of the MSI images were not cloud-free, still the results of the images support the detection of the oil spill of SAR. However, interpretations depend on the date and time of data acquisition, sensor characters including their resolutions and external factors such as winds, waves and currents.

\subsection{Accuracy assessment of oil spill}

Assessment of accuracy of a classified image refers to the extent up to which it agrees with a set of reference data. The results of classification accuracy and Kappa coefficient of different classes of SAR-C and MSI data carried out by confusion matrix are given in Table 1. The Parallelepiped algorithm classified images are given in Fig. 5 in Appendix-B. Table 1a shows the oil spill, seawater and land that are classified over the SAR-C images (Fig. 5a in Appendix-B) acquired before, during and after the oil spill incident. The pixels of the oil spill (CP) is classified to a maximum of $3.92 \%$ over the image acquired on August 10, 2020 after the incident (August 06, 2020) and about $1.64 \%$ on the image acquired on August 16, 2020 when the Wakashio was broken (Table 1). The algorithm did not classify the oil spill over the images acquired before the incident 
Table 1

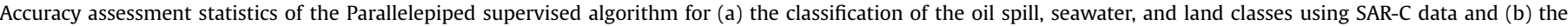

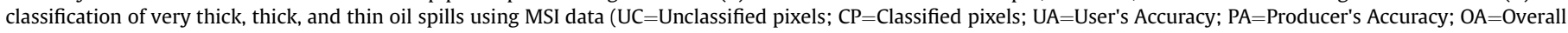
Accuracy; KC-Kappa Coefficient. All values are provided in percentages except the values of KC).

\begin{tabular}{|c|c|c|c|c|c|c|c|c|c|c|c|c|c|}
\hline \multicolumn{14}{|l|}{ (a) } \\
\hline \multicolumn{2}{|c|}{ Date of Acquisition } & \multicolumn{4}{|c|}{ Oil Spill } & \multicolumn{3}{|c|}{ Seawater } & \multicolumn{3}{|l|}{ Land } & \multirow[t]{2}{*}{$\mathrm{OA}$} & \multirow[t]{2}{*}{ KC } \\
\hline & & UC & $\mathrm{CP}$ & UA & PA & $\mathrm{CP}$ & UA & PA & $\mathrm{CP}$ & UA & PA & & \\
\hline \multirow[t]{4}{*}{ After incident } & 15092020 & 0.11 & 0.63 & 90.70 & 100.00 & 63.99 & 88.20 & 99.87 & 35.25 & 100.00 & 91.61 & 94.76 & 0.89 \\
\hline & 03092020 & 2.03 & 3.07 & 100.00 & 99.26 & 61.15 & 100.00 & 99.84 & 33.73 & 100.00 & 99.68 & 99.67 & 0.99 \\
\hline & 22082020 & 0.23 & 2.61 & 95.28 & 100.00 & 60.95 & 100.00 & 96.60 & 36.20 & 99.77 & 99.66 & 99.63 & 0.99 \\
\hline & 21082020 & 0.02 & 4.76 & 93.44 & 100.00 & 58.34 & 99.96 & 99.57 & 36.87 & 99.93 & 98.77 & 99.23 & 0.98 \\
\hline \multirow[t]{2}{*}{ During incident } & 16082020 & 0.08 & 1.64 & 45.69 & 100.00 & 71.00 & 15.57 & 99.52 & 27.27 & 99.94 & 49.37 & 53.68 & 0.14 \\
\hline & 10082020 & 0.07 & 3.92 & 99.54 & 100.00 & 61.68 & 84.37 & 99.88 & 34.30 & 99.88 & 77.07 & 90.36 & 0.83 \\
\hline \multirow[t]{2}{*}{ Before incident } & 17072020 & 0.62 & 0.00 & 0.00 & 0.00 & 64.23 & 99.09 & 99.97 & 35.14 & 100.00 & 97.85 & 98.29 & 0.96 \\
\hline & 05072020 & 0.24 & 0.00 & 0.00 & 0.00 & 64.44 & 97.74 & 99.84 & 35.30 & 99.78 & 96.44 & 98.18 & 0.96 \\
\hline \multicolumn{6}{|l|}{ Average } & & & & & & & 91.72 & 0.84 \\
\hline \multicolumn{14}{|l|}{ (b) } \\
\hline \multicolumn{2}{|c|}{ Date of Acquisition } & \multicolumn{4}{|c|}{ Very Thick Oil Spill } & \multicolumn{3}{|c|}{ Thick Oil Spill } & \multicolumn{3}{|c|}{ Thin Oil Spill } & \multirow[t]{2}{*}{$\mathrm{OA}$} & \multirow[t]{2}{*}{ KC } \\
\hline & & UC & $\mathrm{CP}$ & UA & PA & $\mathrm{CP}$ & UA & PA & $\mathrm{CP}$ & UA & PA & & \\
\hline After incident & 05092020 & 94.37 & 0.03 & 100.00 & 100.00 & 0.08 & 100.00 & 100.00 & 5.50 & 100.00 & 98.00 & 98.38 & 0.95 \\
\hline \multirow[t]{3}{*}{ During incident } & 16082020 & 82.86 & 0.10 & 78.57 & 100.00 & 5.27 & 100.00 & 96.49 & 11.75 & 100.00 & 99.63 & 98.74 & 0.97 \\
\hline & 11082020 & 88.67 & 0.04 & 100.00 & 100.00 & 0.05 & 100.00 & 100.00 & 11.22 & 100.00 & 100.00 & 100.00 & 1.00 \\
\hline & 06082020 & 89.53 & 0.30 & 100.00 & 100.00 & 3.21 & 100.00 & 92.06 & 6.95 & 100.00 & 97.89 & 97.04 & 0.92 \\
\hline \multirow[t]{2}{*}{ Before incident } & 01082020 & 82.16 & 0.00 & 0.00 & 97.85 & 12.48 & 99.45 & 100.00 & 5.35 & 100.00 & 98.15 & 98.50 & 0.96 \\
\hline & 17072020 & 99.85 & 0.00 & 100.00 & 100.00 & 0.00 & 100.00 & 100.00 & 0.12 & 100.00 & 100.00 & 100.00 & 1.00 \\
\hline \multicolumn{2}{|l|}{ Average } & & & & & & & & & & & 98.77 & 0.96 \\
\hline
\end{tabular}

(July 05 and 17, 2020). Moreover, the table shows the largest oil spill that classified over the images acquired during the post-oil spill period, i.e. about $4.76 \%$ and $2.61 \%$ on August 21 and 22 , and $3.07 \%$ and $0.63 \%$ on September 03 and 15,2020 . The classification may be due to the occurrence of the thin oil spill by the expansion of accumulated spilled oil over the water surface by the increase of heat and the spread of thin oil by the hydrodynamic transport process during the period. The classification of pixels for the seawater and land did not show much variation except over the image acquired on August 16, 2020, which showed $71 \%$ of seawater and about $27.27 \%$ of the land (Fig. $5 \mathrm{a}$ in Appendix-B). The study of the Producer's accuracy (PA) of the oil spill, seawater and land classes show an accuracy $>99 \%$ to all classes except for land, which is $77 \%$ and $49 \%$ on August 10 and 16, 2020, respectively. Moreover, the assessment of User's accuracy (UA) shows > 90\% in most classes, and exhibit variation in the classes of the oil spill and seawater that classified over the images acquired on August 16, 2020. The interpretation of the overall accuracy (OA) and Kappa coefficient (KC) for the classified images acquired during and after the oil spill incident show the range between $90.36 \%$ and $99.67 \%$ and $0.83 \%$ and $0.99 \%$, respectively. The classification of images acquired on August 16,2020 produced the lowest OA (53.68\%) and KC (0.14), compared to other images. The observed variation in the accuracy and Kappa coefficient on the image acquired on August 16, 2020 may be due to the detection capability of the SAR-C sensor.

Further, the algorithm applied on the decorrelated images of MSI classified the pixels for the occurrence of the very thick oil spill as $0.30 \%$ on August 06, 2020, during the day of the oil spill incident and about $0.10 \%$ on August 16, 2020 during the day of ship breaking (Table 1b). Similarly, the pixels of the thick oil spill is classified as $3.21 \%$ and $5.27 \%$ on August 06 and 16, 2020, respectively. The assessment of results show the increase of thin oil spill from August 06, 2020 to August 16 during the oil spill incident and decrease towards September 05, 2020, the post-oil spill period (Fig. $5 \mathrm{~b}$ in the Appendix-B). The algorithm misclassified the pixels of the very thick, thick and thin oil spill over the image acquired on August 01, 2020 due to the presence of sediments mixed turbulent water that occurred while aground of Wakashio. The study of Producer's Accuracy shows the values ranging between $92.06 \%$ and $100 \%$ for the classification of the very thick, thick and thin oil spills. The assessment of accuracy for the User's shows the maximum value of $100 \%$ to almost all classes (Table $1 \mathrm{~b}$ ) and suggests that the algorithm can be well utilized in the study of oil spill mapping. The User's accuracy of $0 \%$ is observed for the classification of very thick oil spill on August 01, 2020 when the Producer's Accuracy is 97.85\%, suggesting the absence of very thick oil spill. The producer's and user's accuracies of the MSI data is relatively high when compared with the accuracies of SIR-C data (Table $1 \mathrm{a}$ and $\mathrm{b}$ ). The assessment of Overall accuracy and Kappa coefficient to the classification of very thick, thick and thin oil spills show the minimum of $97.04 \%$ and 0.92 , and maximum of $100 \%$ and 1 , respectively. The averages of Overall accuracy and the Kappa coefficient in the classification by the algorithm are $98.77 \%$ and 0.96 , respectively. The overall study shows the highest values of Overall accuracy and Kappa coefficient in the MSI data $(\mathrm{OA}=98.77 \%$ and $\mathrm{KC}=0.96)$ when compared to the SAR-D data $(\mathrm{OA}=91.72 \%$ and $\mathrm{KC}=0.84)$, indicating that the Sentinel-2 image is classified more accurately.

\section{Validation of oil spill mapping}

The lagoon morphology of Mauritius Island varies from a single lagoon consisting of a sandy beach and a reef zone to complex systems comprising of a variety of habitats including beaches, mangroves, sand or mud swamps, lagoon channels, seagrass beds, coral colonies, sand beds and a reef zone (Daby, 2003, 2006). The aerial photographs taken during the event evidence that the Wakashio ran aground on a coral reef and the leaking of oil from the ship started after cracks developed in its hull (Fig. 8a and b). The photographs show clearly 1 ) the location of incident is near to the coral reef ridge, where waves break as interpreted over the SAR images (Fig. 3) and 2) the occurrence of oil spill from the ship and its spread in and around of ship is as studied by the MSI images acquired on August 06, 2020 (Figs. 3 and 5 to 7). The different thicknesses of oil spills (very thick, thick and thin) can be identified 

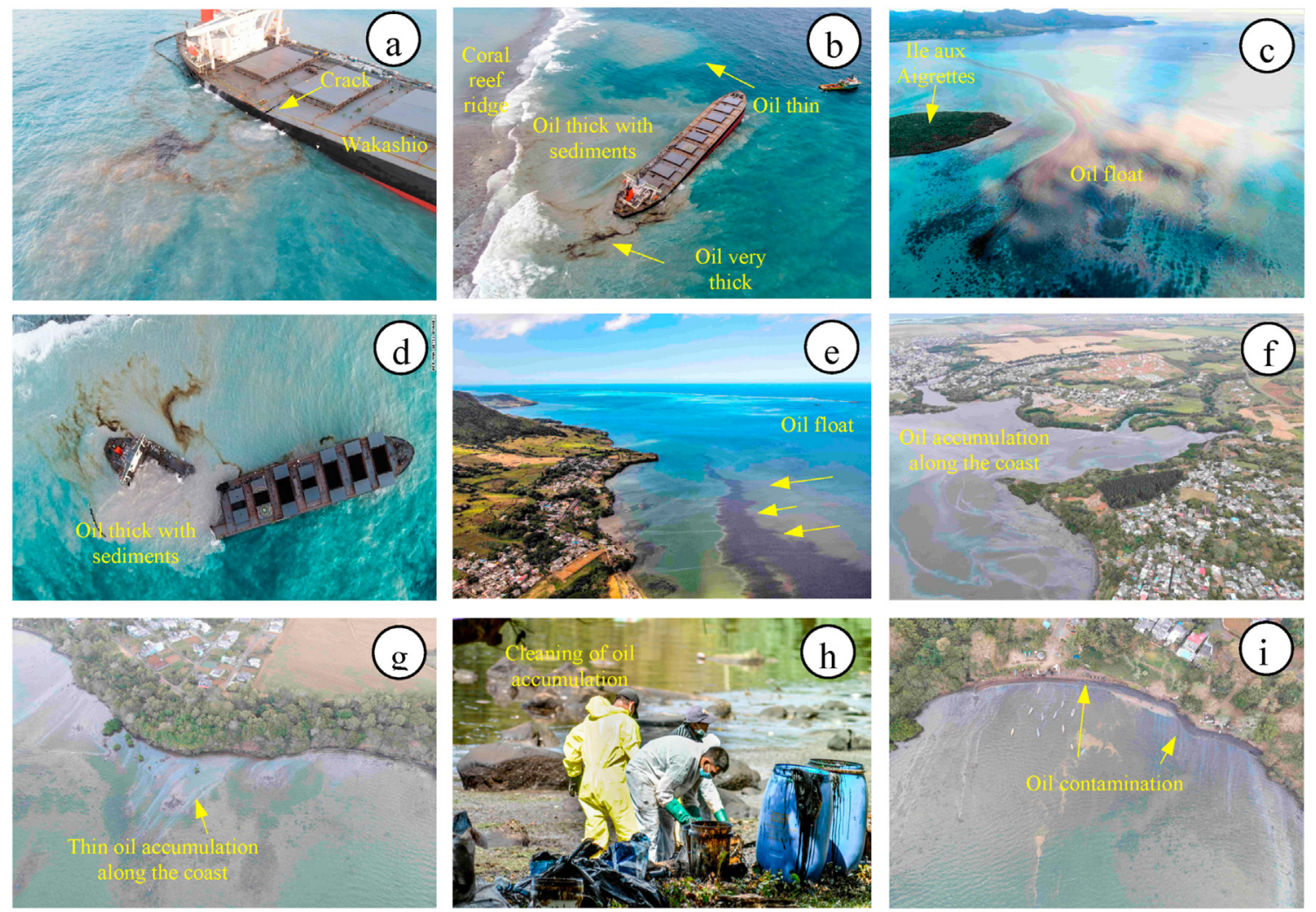

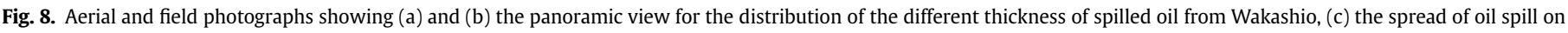

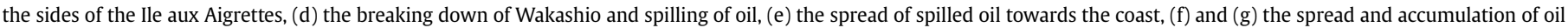
along the coast, (h) the removing of oil by volunteers, and (i) the contamination of oil in the southeast coast of Mauritius.

in the photographs as interpreted by the decorrelated images of MSI data (Figs. 8b and 7c). The spilled oil was pushed by waves towards the lagoon crossing the coral reef ridge. The interpretation of oil spills that spread both the sides of Ile aux Aigrettes, over the lagoon and coral reefs and along the coast using Sentinel data can be studied by aerial photographs (Fig. 8c, e, f \& g) also. The breaking of the ship into two parts and spread of oil as shown in Fig. 8d has been as well interpreted over the images acquired on August 16, 2020. Fig. 8b and d shows the location of oil spill site and waves breaking at the reef ridge, and thereby confirming the interpretation of SAR images (Fig. 3). In addition, the spread of oil towards the coast and accumulation of oil along the coast could be observed from the photographs (Fig. 8e, f, g). The field photographs show the collection of spilled oil by the volunteers to protect the accumulation of oil along the coast (Fig. 8h) and contamination of oil over the sediments, fauna and flora (Fig. 8e, f, g \& i). The field photographs further allow us to assess the impacts of oil accumulation found along the coast.

\section{Conclusions}

In this study, we detected the oil spill that occurred on July 25 , 2020 , in the offshore region near the Pointe d'Esny, southeast coast of Mauritius Island using the SAR data of Sentinel-1 and MSI data of Sentinel-2 acquired before, during and after the incident. The SAR images exhibited the Wakashio as a bright object in the longitudinal orientation and the oil spill as dark patches with spreading widths. The images showed clearly the accumulation of spilled oil along the coast. The study of the image spectra of MSI showed that bands 3 and 4 are characteristics to the absorption of oil spills. The developed band ratios images exhibited the types of oil spills and showed the spread of oil spills from the incident site to the coast. The decorrelated images well detected the thin thick and very thick types of oil spills, spread over the lagoon and coral reefs and the accumulation of oil along the coast between Blue Bay and Beau Champ. The MSI images exhibited very thick, thick and thin oil spills and the occurrence of spills around the ship offshore. The study of images acquired after 21 August 2020 showed the occurrence and distribution of post-oil spill in the region.

The results of the MSI images with the results of SAR images showed that the SAR images did not exhibit the occurrence of spills around the ship and offshore. The SAR C-band penetrated the clouds and best detected the oil spill and showed the direction of wind and wave approach due to VV polarization and high dielectric property, compared with the results of MSI images. An assessment of accuracy has been carried out for mapping the oil spill by SAR-C and MSI data using Parallelepiped supervised algorithm. The accuracy assessment of oil spills, seawater and land using SAR-C data provided the overall accuracy of $91.72 \%$ and Kappa coefficient of 0.84 . The assessment of accuracy in the classification of very thick, thick and thin oil spills using the decorrelated images of MSI provided the overall accuracy of 98.77 and Kappa coefficient of 0.96 . The results of MSI supported the detection of oil spills of SAR. The data of Sentinel-1 and 2 collected before, during and after confirmed the oil spill event and occurrence, spread and accumulation of the spill. All the results were validated using the aerial and field photographs taken during the incident. This study demonstrated the application of Sentinel- 1 and 2 sensors and the potential of image processing methods to monitor and assess the oil spill. 


\section{Credit author statement}

Sankaran Rajendran: Conceptualization, Methodology, Data Analysis and Interpretation and Writing Original draft. Ponnumony Vethamony: Reviewing, Editing, Visualization and Investigation. Fadhil N. Sadooni: Reviewing, Visualization and Investigation. Hamad Al-Saad Al-Kuwari: Reviewing and Investigation. Jassim A. Al-Khayat: Reviewing and Visualization. Vashist O. Seegobin: Validation, Reviewing and Editing. Himanshu Govil: Analysis and Reviewing. Sobhi Nasir: Reviewing and Editing.

\section{Declaration of competing interest}

The authors declare that they have no known competing financial interests or personal relationships that could have appeared to influence the work reported in this paper.

\section{Acknowledgment}

This work was supported by the Qatar University's International Research Collaboration Co-Funds project (IRCC-2019-002). The authors are thankful to the Copernicus, European Space Agency (https://sentinel.esa.int/web/sentinel/sentinel-data-access) for sharing the Sentinel data through sentinel open access hub. The authors are very much thankful to Prof. Maria Cristina Fossi, the Editor and anonymous reviewers of the journal for their valuable reviews, providing constructive comments and suggestions that have helped to present the work lucidly.

\section{Appendix A and B. Supplementary data}

Supplementary data to this article can be found online at https://doi.org/10.1016/j.envpol.2021.116618.

\section{References}

Abrams, M.J., Rothery, D.A., Pontual, A., 1988. Mapping in the Oman ophiolite using enhanced Landsat Thematic Mapper images. Tectonophysics 151, 387-401. https://doi.org/10.1016/0040-1951(88)90254-5.

AFP (Agence France-Presse), 2020a. Mauritius Facing Environmental Crisis as Shipwreck Leaks Oil, 7 August 2020. https://www.theguardian.com/. (Accessed 8 August 2020).

AFP (Agence France-Presse), 2020b. Damaged Ship Leaking Oil off Mauritius Could Break up, Says PM, 10 August 2020. https://www.theguardian.com/. (Accessed 12 August 2020).

Akinwumiju, S.A., Adelodun, A.A., Ogundeji, S.E., 2020. Geospatial assessment of oil spill pollution in the Niger Delta of Nigeria: an evidence-based evaluation of causes and potential remedies. Environ. Pollut. 267, 115545. https://doi.org/ 10.1016/j.envpol.2020.115545.

Alpers, W., Holt, B., Zeng, K., 2017. Oil spill detection by imaging radars: challenges and pitfalls. Rem. Sens. Environ. 201, 133-147. https://doi.org/10.1016/ j.rse.2017.09.002.

Arellano, P., Tansey, K., Balzter, H., Boyd, D.S., 2015. Detecting the effects of hydrocarbon pollution in the Amazon forest using hyperspectral satellite images. Environ. Pollut. 205, 225-239. https://doi.org/10.1016/j.envpol.2015.05.041.

Arslan, N., 2018. Assessment of oil spills using Sentinel 1 C-band SAR and Landsat 8 multispectral sensors. Environ. Monit. Assess. 190, 637. https://doi.org/10.1016/ j.envpol.2015.05.041.

Bayramov, E., Kada, M., Buchroithner, M., 2018. Monitoring oil spill hotspots, contamination probability modelling and assessment of coastal impacts in the Caspian sea using SENTINEL-1, LANDSAT-8, RADARSAT, ENVISAT and ERS satellite sensors. J. Operat. Oceanogr. 11 (1), 27-43. https://doi.org/10.1080/ 1755876X.2018.1438343.

Bhangale, U., Durbha, S.S., King, R.L., Younan, N.H., Vatsavai, R., 2017. High-performance GPU computing-based approaches for oil spill detection from multitemporal remote sensing data. Rem. Sens. 202, 28-44. https://doi.org/ 10.1016/j.rse.2017.03.024

Bradford, B.N., Sanchez-Reyes, P.J., 2011. Automated oil spill detection with multispectral imagery. Proc. SPIE-Int. Soc. Opt. Eng. 8030. https://doi.org/10.1117/ 12.883393, 2011.

Castillejo-Gonzalez, I.L., Lopez-Granados, F., Garcia-Ferrer, A., Pena-Barragan, J.M., Jurado-Exposito, M., de la Orden, M.S., Gonzalez-Audicana, M., 2009. Objectand pixel-based analysis for mapping crops and their agro-environmental associated measures using QuickBird imagery. Comput. Electron. Agric. 68,
207-215. https://doi.org/10.1016/j.compag.2009.06.004.

Chaturvedi, S.K., Banerjee, S., Lele, S., 2020. An assessment of oil spill detection using Sentinel 1 SAR-C images. J. Ocean Eng. Sci. 5, 116-135. https://doi.org/ 10.1016/j.joes.2019.09.004.

Clark, R.N., Swayze, G.A., Leifer, I., Livo, K.E., Kokaly, R., Hoefen, T., Lundeen, S., Eastwood, M., Green, R.O., Pearson, N., 2010. A method for quantitative mapping of thick oil spills using imaging spectroscopy. USGS Open File Rep. 1167 (2010), 1-51. https://doi.org/10.3133/ofr20101167.

Congalton, R.G., 1991. A review of assessing the accuracy of classifications of remotely sensed data. Remote Sens. Environ. 37 (1), 35-46. https://doi.org/ 10.1016/0034-4257(91)90048-B.

Daby, D., 2006. Current patterns and the distribution of benthic habitats in a coastal lagoon of Mauritius. Hydrobiologia 556, 47-60. https://doi.org/10.1007/s10750005-0593-7.

Daby, D., 2003. Effects of seagrass bed removal for tourism purposes in a Mauritian bay. Environ. Pollut. 125, 313-324. https://doi.org/10.1016/S0269-7491(03) 00125-8.

El-Magd, I.A., Zakzouk, M., Abdulaziz, A.M., Ali, E.M., 2020. The potentiality of operational mapping of oil pollution in the Mediterranean sea near the entrance of the Suez canal using sentinel-1 SAR data. Rem. Sens. 12, 1352. https://doi.org/10.3390/rs12081352.

ESA, 2020. Applications: Arctic Circle Oil Spill. Dated 05 June 2020. European Space Agency. Available at. http://www.esa.int/ESA_Multimedia/Images/2020/06/ Arctic_Circle_oil_spill.

Fingas, M.F., Brown, C., 2018. A Review of oil spill remote sensing. Sensors 18 (1), 91. https://doi.org/10.3390/s18010091.

Ganasria, B.P., Dwarakisha, G.S., 2015. Study of land use/land cover dynamics through classification algorithms for Harangi catchment area, Karnataka State, India. Aquatic Procedia 4, 1413-1420. https://doi.org/10.1016/ j.aqpro.2015.02.183.

Garcia-Pineda, O., Holmes, J., Rissing, M., Jones, R., Wobus, C., Svejkovsky, J., Hess, M., 2017. Detection of oil near shorelines during the deepwater horizon oil spill using synthetic aperture radar (SAR). Rem. Sens. 9 (6), 567. https://doi.org/ $10.3390 /$ rs9060567.

Garcia-Pineda, O., Staples, G., Jones, C.E., Hu, C., Holt, B., Kourafalou, V., Graettinger, G., DiPinto, L., Ramirez, E., Streett, D., Cho, J., Swayze, G.A., Sun, S., Garcia, d., Haces-Garcia, F., 2020. Classification of oil spill by thicknesses using multiple remote sensors. Rem. Sens. Environ. 236, 111421. https://doi.org/ 10.1016/j.rse.2019.111421.

Gillespie, A.R., Kahle, A.B., Walker, R.E., 1986. Color enhancement of highly correlated images. 1. Decorrelation and HSI contrast stretches. Remote Sens. Environ. 20, 209-735. https://doi.org/10.1016/0034-4257(86)90044-1.

Hand, M., 2020. Wakashio Forward Hull Section Scuttled off Mauritius. Seatrade Maritime News. Accessed on. https://www.seatrade-maritime.com/casualty/ wakashio-forward-hull-section-scuttled-mauritius. (Accessed 25 August 2020).

Klemas, V., 2010. Tracking oil slicks and predicting their trajectories using remote sensors and models: case studies of the sea princess and deepwater horizon oil spills. J. Coast Res. 26, 789-797. https://doi.org/10.2112/10A-00012.1.

Kolokoussis, P., Karathanassi, V., 2018. Oil spill detection and mapping using sentinel 2 imagery. J. Mar. Sci. Eng. 6 (1), 4. https://doi.org/10.3390/ jmse6010004.

Lang, H., Zhang, X., Xi, Y., Zhang, X., Li, W., 2017. Dark-spot segmentation for oil spill detection based on multi-feature fusion classification in single-pol synthetic aperture radar imagery. J. Appl. Remote Sens. 11, 015006 https://doi.org/10.1117/ 1.JRS.11.015006.

Lee, J.K., Acharya, T.D., Lee, D.G., 2018. Exploring land cover classification accuracy of landsat 8 image using spectral index layer stacking in hilly region of South Korea. Sensor. Mater. 30 (12), 2927-2941. https://doi.org/10.18494/ SAM.2018.1934.

Lewis, D., 2020. Cleaning up after Mauritius oil spill. Nature 585, 172. https:// doi.org/10.1038/d41586-020-02446-7.

Liu, D., Zhang, J., Wang, X., 2016. Reference spectral signature selection using density-based cluster for automatic oil spill detection in hyperspectral images. Optic Express 24 (7), 7411-7425. https://doi.org/10.1364/OE.24.007411.

Lu, Y., Liu, J., Ding, J., Shi1, J., Chen, J., Ye, X., 2019. Optical remote identification of spilled oils from the SANCHI oil tanker collision in the East China Sea. Chin. Sci. Bull. 64 (31), 3213-3222. https://doi.org/10.1360/N972019-00094 (in Chinese).

Lu, Y.-C., Tian, Q.-J., Wang, J.-J., Wang, X.-C., Qi, X.-P., 2008. Experimental study on spectral responses of offshore oil slick. Chin. Sci. Bull. 53, 3937-3941. https:// doi.org/10.1007/s11434-008-0515-y.

Lu, Y.C., Tian, Q.J., Qi, P.X., Wang, J.J., Wang, A.C., 2009. The spectral response analysis of offshore thin oil slicks. Spectrosc. Spectr. Anal. 29 (4), 986-989. https:// doi.org/10.3964/j.issn.1000-0593(2009)04-0986-04 (in Chinese).

Lu, Y., Tian, Q., Wang, X., Zhenga, G., Li, X., 2013a. Determining oil slick thickness using hyperspectral remote sensing in the Bohai Sea of China. Int. J. Digital Earth 6, 76-93. https://doi.org/10.1080/17538947.2012.695404.

Lu, Y.C., Li, X., Tian, Q., Zheng, G., Sun, S., Liu, y., Yang, Q., 2013b. Progress in marine oil spill optical remote sensing: detected targets, spectral response characteristics, and theories. Mar. Geodes. 36 (3), 334-346. https://doi.org/10.1080/ 01490419.2013.793633.

Ma, L., Li, Y., Liu, Y., 2009. Oil spill monitoring based on its spectral characteristics. Environ. Forensics 10, 317-323. https://doi.org/10.1080/15275920903347024.

Mdakane, L.W., Kleynhans, W., 2020. Feature selection and classification of oil spill from vessels using sentinel-1 wide-swath synthetic aperture radar data. Geosci. Rem. Sens. Lett. IEEE. https://doi.org/10.1109/LGRS.2020.3025641. 
Nadia, T., Taher, S., Mohammed, A., Masomeh, R., 2018. Investigation of proper index of oil spill detection using space-borne sentinel-2 (case study: the Persian Gulf, 15 Feb 2016). J. Oceanogr. 9 (33), 31-40. https://doi.org/10.29252/JOC.9.33.31.

Otremba, Z., Zielinski, O., Hu, C., 2013. Optical contrast of oil dispersed in seawater under windy conditions. J. Eur. Opt. Soc. 8, 13051. https://doi.org/10.2971/ jeos.2013.13051.

Otremba, Z., Piskozub, J., 2001. Modelling of the optical contrast of an oil film on a sea surface. Optic Express 9 (8), 411-416. https://doi.org/10.1364/OE.9.000411.

Ozigis, M.S., Kaduk, J.D., Jarvis, C.H., Conceiçao Bispo, P., Balzter, H., 2020. Detection of oil pollution impacts on vegetation using multifrequency SAR, multispectral images with fuzzy forest and random forest methods. Environ. Pollut. 256, 113360. https://doi.org/10.1016/j.envpol.2019.113360.

Ozigis, M.S., Kaduk, J.D., Jarvis, C.H., 2019. Mapping terrestrial oil spill impact using machine learning random forest and Landsat 8 OLI imagery: a case site within the Niger Delta region of Nigeria. Environ. Sci. Pollut. Control Ser. 26, 3621-3635. https://doi.org/10.1007/s11356-018-3824-y.

Pisano, A., Bignami, F., Santoleri, R., 2015. Oil spill detection in glint-contaminated near-infrared MODIS imagery. Rem. Sens. 7, 1112-1134. https://doi.org/ 10.3390/rs70101112.

Prastyani, R., Basith, A., 2018. Utilisation of sentinel-1 SAR imagery for oil spill mapping: a case study of Balikpapan bay oil spill. J. Geospatial Inf. Sci. Eng. 1 (1), 22-26. https://doi.org/10.22146/jgise.38533.

Rajendran, S., Sadooni, F.n., Al-Kuwari, H.A., Oleg, A., Govil, h., Nasir, S., Vethamony, P., 2020a. Monitoring Oil Spill in Norilsk, Russia Using Satellite Data (Accepted in Scientific Reports).

Rajendran, S., Vethamony, P., Sadooni, F.N., Al Saad, Hamad, Al-Khayat, Jassim A., Govil, H., Nasir, S., 2020b. Sentinel-2 Image Transformation Methods for Mapping Oil Spill - A Case Study to Wakashio Oil Spill, Mauritius Island (Indian Ocean. Submitted to MethosX as co-submission).

Rajendran, S., Nasir, S., El-Ghali, M., Alzebdah, K., Al-Rajhi, A.S., Al-Battashi, M., 2018. Spectral signature characterization and remote mapping of Oman exotic limestones for industrial rock resource assessment. Geosciences 8 (145), 1-18. https://doi.org/10.3390/geosciences8040145.

Rajendran, S., 2016. Mapping of Neoproterozoic source rocks of the Huqf Supergroup in the Sultanate of Oman using remote sensing. Ore Geol. Rev. 78, 281-299. https://doi.org/10.1016/j.oregeorev.2016.03.024.

Rajendran, S., Al-Sayigh, A.R., Al-Awadhi, T., 2016. Vegetation analysis study in and around Sultan Qaboos University, Oman, using Geoeye-1 satellite data. Egypt. J. Rem. Sens. Space Sci. 19, 297-311. https://doi.org/10.1016/j.ejrs.2016.03.005.

Rajendran, S., Nasir, S., Kusky, T.M., Ghulam, A., Gabr, S., El Ghali, M., 2013. Detection of hydrothermal mineralized zones associated with Listwaenites rocks in Central Oman using ASTER data. Ore Geol. Rev. 53, 470-488. https://doi.org/ 10.1016/j.oregeorev.2013.02.008.

Rajendran, S., Al-Khirbash, S., Bernhard, P., Nasir, S., Al-Abri, A.H., Kusky, T.M.,
Ghulam, A., 2012. ASTER detection of chromite bearing mineralized zones in Semail Ophiolite Massifs of the northern Oman Mountain: exploration strategy. Ore Geol. Rev. 44, 121-135. https://doi.org/10.1016/j.oregeorev.2011.09.010.

Rajendran, S., Thirunavukkarasu, A., Balamurugan, G., Shankar, K., 2011. Discrimination of iron ore deposits of granulite terrain of Southern Peninsular India using ASTER data. J. Asian Earth Sci. 41, 99-106. https://doi.org/10.1016/ j.jseaes.2011.01.004.

Richards, J.A., Jia, X., 1999. Remote Sensing Digital Image Analysis: an Introduction Springer, p. 363. https://doi.org/10.1007/978-3-662-03978-6. Berlin; Heidelberg; New York; Barcelona; Hong Kong; London; Milan; Paris; Singapore; Tokyo.

Rothery, D.A., 1987. Decorrelation stretching an aid to image interpretation. Int. J. Rem. Sens. 8, 1253-1254. https://doi.org/10.1080/01431168708954771.

Stopa, J.E., Mouche, A., 2017. Significant wave heights from Sentinel-1 SAR: validation and applications. J. Geophys. Res. Oceans 122 (3), 1827-1848. https:// doi.org/10.1002/2016JC012364.

Sun, S., Lu, Y., Liu, Y., Wang, M., Hu, C., 2018a. Tracking an oil tanker collision and spilled oils in the East China Sea using multisensor day and night satellite imagery. Geophys. Res. Lett. 45, 3212-3220. https://doi.org/10.1002/ 2018GL077433.

Sun, S., Hu, C., Garcia-Pineda, O., Kourafalou, V., Le Hénaff, M., Androulidakis, Y. 2018b. Remote sensing assessment of oil spills near a damaged platform in the Gulf of Mexico. Mar. Pollut. Bull. 136, 141-151. https://doi.org/10.1016/ j.marpolbul.2018.09.004.

Sun, Z.Q., Zhao, Y.S., Yan, G.Q., Li, S.P., 2011. Study on the hyperspectral polarized reflection characteristics of oil slicks on sea surfaces. Chin. Sci. Bull. 56 1596-1602. https://doi.org/10.1007/s11434-010-4112-5.

Suneel, V., Trinadha Rao, V., Suresh, Gopika, Aditya Chaudhary, R., Vethamony, P., Ratheesh, P., 2019. Oil pollution in the Eastern Arabian Sea from invisible sources: a multi-technique approach. Mar. Pollut. Bull. 146, 683-695. https:// doi.org/10.1016/j.marpolbul.2019.07.015.

Vergara, L., Soriano, A., Safont, G., Salazar, A., 2016. On the fusion of nonindependent detectors. Digit. Signal Process. 50, 24-33. https://doi.org 10.1016/j.dsp.2015.11.009.

Weiß, T., Ramsauer, T., Löw, A., Marzahn, P., 2020. Evaluation of different radiative transfer models for microwave backscatter estimation of wheat fields. Rem. Sens. 12, 3037. https://doi.org/10.3390/rs12183037.

Xue, S., Geng, X., Yan, X., et al., 2020. Significant wave height retrieval from Sentinel-1 SAR imagery by convolutional neural network. J. Oceanogr. https:// doi.org/10.1007/s10872-020-00557-3.

Zhang, Y., Li, Y., San Liang, X., Tsou, J., 2017. Comparison of oil spill classifications using fully and compact polarimetric SAR images. Appl. Sci. 7, 193. https:// doi.org/10.3390/app7020193. 